\title{
The Absurdity of Aspiration within Further Education in England: Where Much is Said but Little is Done?
}

\author{
Nick Wragg $^{1 *}$ Dr John Stoszkowski ${ }^{2}$ Dr Áine MacNamara ${ }^{3}$ \\ 1.School of Business, Grimsby Institute of FHE, North East Lincolnshire, UK. \\ 2.School of Sport and Health Sciences, University of Central Lancashire, Preston, UK. \\ 3.School of Health and Human Performance, Dublin City University, Dublin, Ireland
}

\begin{abstract}
In the last 20 years, considerable research and ideological focus has been placed on aspiration initiatives in Further Education (FE) in England. Unfortunately, the label of "aspiration" is often misunderstood, and the liberal overuse of the term is largely offered as a panacea for improving the academic and life outcomes of young people, which has resulted in a paucity of studies that examine application of the concept. This discussion paper explores how current aspirational doctrine plays out within FE in England and suggests that, although student aspirations are widely lauded as important, there is a lack of understanding of the practical application of aspirational strategies. We suggest the notion of "raising aspirations" has been condensed to little more than an incitement to action that oversimplifies complexities and ignores the burden of historical social influencers on students. Consequently, we argue that a more sophisticated analysis of aspiration is needed, as well as a wider debate involving relevant stakeholders on the practicalities of what constitutes aspirational strategy.
\end{abstract}

Keywords: aspiration, widening participation, further education

DOI: $10.7176 / \mathrm{JEP} / 11-9-13$

Publication date:March $31^{\text {st }} 2020$

\section{Introduction}

FE's special focus is on bridging the link between school and work-supporting people to gain the vocational qualifications and skills they need to secure and progress in employment or learning. In many cases this requires inspiring and educating a diverse range of young people including those with special educational needs (SEN), or those who have left school disengaged and without qualifications.

Department for Business, Innovation and Skills $(2014,4)$

The continuing political debate on the place and purpose of Further Education (FE) and its funding highlights the dichotomous nature of the sector. On the one hand, FE provision is often lauded across the political spectrum as being invaluable to local communities and vital for the economy in terms of promoting skills, social capital and social justice (e.g., Further Education Workforce Strategy 2014). On the other hand, however, FE has been subjected to spending cuts of $£ 3.3$ billion since 2010 and is constantly battling against an intellectual arrogance (e.g., Appadurai 2004; Zipin et al. 2015) that serves to undermine FE provision (Robinson 2017). The notion of student aspiration exemplifies this divided landscape; although it is seen as crucial to student achievement within education, in practical terms it has largely been ignored (Richardson 2007).

The last 20 years has seen a considerable research (Campbell \& McKendrick 2017) and applied (Wilde 2014) focus on aspiration initiatives in FE settings in England. Unfortunately, as argued elsewhere (e.g., Archer et al. 2007; Croll 2008), the liberal overuse of, what we propose to be a misunderstood label of aspiration, is often offered as a panacea for improving the academic and life outcomes of young people. This is despite a relative paucity of studies examining the application of aspiration research and initiatives in FE in England. As such, in this discussion paper we focus on how current aspirational doctrine (Gale \& Parker 2015; Spohrer 2011) plays out in practice within FE. Simply, is it the case that student aspirations are widely lauded as important but there is a lack of understanding of the practical application of this field of research?

To understand the importance of an aspirational agenda within an FE setting it is necessary to appreciate how the sector has evolved to its current iteration. A defining moment within the FE sector over the last thirty years was the Further and Higher Education Act 1992, which proposed a new paradigm of administrative and financial freedom for colleges by way of incorporation and removal of Local Authority (LA) control. This was part of the prevailing governmental philosophy at the time of welfare re-structure, influenced by the " 3 Es" ideological agenda - Economy, Efficiency, and Effectiveness, which was a key driver in public services reform (Mather \& Seifert 2004). One of the most culturally significant changes that has emerged since the 1992 Act has been the establishment of student as consumer along with a corresponding move within the sector from professionalism to managerialism (Randle \& Brady 1997). In essence, this has resulted in the manifestation of a profit prerogative within the Further and Higher Education (FHE) "quasi-market". Additionally, a decade of political and social austerity measures has contributed to continual downward pressure on funding for the sector and FE colleges have reacted to protect their existence. One example of the effect of austerity is the increase in mergers between colleges 
within geographical boundaries in order to create economies of scale and rationalisation in pursuit of ensuring value for money (Collins 2015). Looking ahead, there are clear financial concerns for the sector that jeopardise the long-term future of FE (Collins 2015). Dennis $(2016,1)$ concurs, stating that:

FE colleges persist in a diminished form within a learning economy. In response to the managerial onslaught, the sector has adopted an ethics of survival, a necessary response to austerity and deregulation.

The continuing reduction of government funding within the FE sector has also had an eviscerating effect on governance, with data suggesting that FE colleges will have experienced a shrinkage in budget of $43 \%$ by the end of 2018 (Keep 2014). The result of consumer choice and governmental spending cuts may have succeeded in driving the intended economies of scale, but in doing so has, by default, largely ignored aspects relating to the human cost of the change, both in terms of student provision and learning standards (Norris \& Adam 2017). Reflecting a similar focus on league tables and "raising grades" within secondary education, a performative culture is now apparent in many FE colleges (Lea \& Simmons 2012). Kaufman (2014) reflects on an educational landscape where emotional education is, in part, subjugated to assuage educational performance and survival, with the dual aspects in practice largely occupying a mutually exclusive status, and a dominant culture of measurement diminishing the importance of inspiration in enabling potential. In essence, the general agreement across business and industry is that sections of the student population, by the age of 18 , are largely unprepared for the workplace and leave compulsory education with poor literacy and numeracy skills (Kuczera, Field \& Windisch 2016). Juxtaposed against the macro and socio-economic backdrop within FE, the sector is nevertheless promoted as a key agent in addressing this skill gap (Robinson 2018).

\section{Student Aspiration with FE}

Quaglia \& Cobb $(1996,127)$ suggest that a student's aspirations can be defined as their "ability to identify and set goals for the future, while being inspired in the present to work towards those goals". Therefore, aspiration is what an individual "hopes" will happen in the future (Gorard et al. 2012). Unfortunately, the future hopes of students within an FE setting remain mired in a wealth of political rhetoric, where the raising of student aspiration is represented as a panacea for developing a well-educated and highly skilled workforce, capable of contributing towards the United Kingdom's (UK) knowledge-dependent economy (Spohrer 2011; Baird et al. 2012). This "magic bullet" approach is especially apparent when there is a low aspiration "deficit model" surrounding socalled disadvantaged students, for instance from a widening participation (WP), special educational needs (SEN), or more generally termed low socioeconomic status (SES) background (Atkins 2010). Zipin et al. (2015) further argues that to condense this notion of "raising aspirations" to nothing more than an incitement to action, while at the same time suggesting that this in itself provides the means for students to overcome career and life obstacles, oversimplifies the complexities of the situation and ignores the burdening of historical social influencers on both middle and working class. Importantly, the prevailing focus on the raising of aspirations fails to properly address the question "raising from what, to where?" and if the panacea of aspiration is to be more than simply a label of convenient political buzzword, more needs to be done to understand its nuances. Indeed, practical application of aspiration that moves beyond the current linear ideological dialogue is required.

Aspiration can therefore be argued to be "State" business, based on an historical succession of governmental imperatives that requires consistent national economic growth to ensure a level of individual and social prosperity, brought about by an investment in human capital (Rose \& Baird 2013). However, governmental attempts to clearly define "aspiration" remain ambiguous (see for example The White Paper on Education: The Importance of Teaching; DfE 2010). Equally, within academic discourse similar syntactic disparities and uncertainties exist, and these can hide or subsume the everyday life complexities that students face and by which they are influenced (Archer et al. 2007; Stahl 2012).

It is also important to consider the positioning of the student within this discourse. "Aspiration" in its noun state suggests a passivity, where the student is seen as a "victim" of cultural chance and circumstance and remains extrinsically tied to what others, for example the government, want the individual to achieve. In this regard, aspiration can be seen as a casting of human capital somehow in deficit. As Spohrer $(2016,412)$ points out,

neoliberal trends of shifting responsibility for a 'good life' to the individual have intensified [with] the pressure on individuals to demonstrate aspiration or be damned, greater than ever.

Conversely, discourse around individual aspiration deficit places the concept of aspiration within the realms of a lack of personal motivation, and this mirrors prevailing government ideology that individuals have a responsibility, or duty in and of themselves, to achieve and succeed in life. Furthermore, low aspiration is seen as symptomatic of the working class or living within socially deprived areas (Grant 2017). This thinking casts aspiration in the verb state, to aspire, implying a movement towards something that is reflective of the original derivation of the word aspirare, to "seek to reach". In this regard and reflecting Eccles' (2009) expectancy value model of motivated behavioural choice, the development of aspirations is influenced by an individual's context, identity, and self-concept (Elliot \& Dweck 2005). Taking Payne's (2003) conceptualisation of pragmatic rationality as its base, the role of subjective perception here is emphasised, but also acknowledged is the existence 
of environmental factors and rational choice, or the "wider actors, institutions and processes" that influence student lives (Grant 2017, 290). All of which emphasises the inherent complexity of aspiration, with Zipin et al. (2015, 228) arguing that research needs to consider the:

complex understanding of how aspirations are constituted by multiple social-cultural resources, including policy and populist ideologies but also family and community histories and the lived-cultural agency of people in the present.

To further highlight some of these complexities, Payne (2003) offers three distinct strands of aspiration as either structuralist - choices governed by environmental factors; economic - choices governed by rationality; and pragmatic - limitations placed upon choice by structure, opportunity and qualifications. This illustrates how the manner in which aspiration is acknowledged can vary extensively depending on the research. Indeed, Gale \& Parker $(2015,140)$ call for a "more nuanced, robust conception of aspiration", and themselves further identify six accounts of the term aspiration.

This apparent difficulty in even agreeing on terminology is therefore non-productive when determining how to implement practical strategies to influence student aspiration. One possible start point is to acknowledge that an important consideration when evaluating and defining precise terminology, is to acknowledge that aspiration is largely representative of the condition of the individual and that as a concept for wider or deeper investigation as to its effects is understandably problematic (St Clair et al. 2013). However, this does not diminish the importance of any synergy between extrinsic and intrinsic variables, with the notion of an aspiration towards occupational outcome largely influenced and mediated by personal choices and decisions, as well as the personality characteristics of the students entering these occupations (Croll \& Attwood 2013).

Importantly, each of these life influencers is not mutually exclusive. There are, for example, different theoretical viewpoints on the understanding around educational aspirations and their significance for future behaviour. Strand \& Winston (2008), for instance, consider the dominant model to be the "status attainment" model which suggests that aspirations are a cognitive state that motivate students towards attaining academic success. Reflecting earlier comments, this approach recognises both personal dimensions and social dimensions as being fundamental mediating factors. Further, it is suggested that economic models portray educational aspirations as a purely rational assessment of students' economic and social circumstances, thereby excluding any intrinsic notion of self-motivation, and ignoring the influence of self within the aspirational arena.

In summary, the discourse on student aspiration tends to dogmatically focus on how aspiration can be "raised", with a resulting emphasis on an individual's career(s). This is a rational state-approach based on the previously mentioned need for global competitiveness and efficient economic productivity. Governments are politically incentivised towards helping resolve the UK "productivity puzzle" (i.e., the enduring productivity deficit in relation to comparable economies), which dominates current political thinking, and so seek a return from investing in education. Aspiration, therefore, appears to be the banner under which governments rally the troops.

\subsection{Aspiration and the Political Narrative}

While much has been written on the place of aspiration within education, less has been applied to FE as a sector. As such, FE within England is an important area in which to examine the concept of aspiration, especially given the current focus on widening participation. As discussed previously, low aspiration is associated with SES students who represent a strong demographic focus within FE colleges. However, it could be argued that this perception may not be wholly accurate.

FE research often fails to recognise that raising student aspiration in practical terms is problematic. Initiatives often ignore intrinsic individual complexities and focus instead on organisational performative standards, budgets, and business plans (Warner \& Crosthwaite 1995). However, it has been shown that despite this obfuscation, the concept of aspiration sits at the forefront of the political narrative and is argued to be central to the raising of student skills. Indeed, many measures have been implemented since the Labour government first introduced a range of initiatives based on the principle of raising aspiration over twenty years ago, see for example Aiming High for Young People (HM Treasury \& DCSF 2007); New Opportunities: Fair Chances for the Future (Cabinet Office 2009) and Inspiring Communities (Department for Communities and Local government et al. (2009). More recently, the then Prime Minister May (2018) stated "how vital, good schools and colleges are to a community and how the hopes and aspirations which parents have for their children are bound up with the qualities of education on offer".

Despite this political focus, other influencing factors such as the macro-economic shock in the aftermath of the financial crisis of 2007, and the subsequent uncertainty following the UK's European Union membership referendum have adversely affected the potential provision of skilled workers, creating "a crossroads in terms of meeting...future labour market need" (Anderson 2017, 5). In 2015, the Employers Skills Survey (UKCES 2016) reported that $64 \%$ of employers surveyed cited difficulties in recruiting applicants with the requisite skills and knowledge. This serves to set a scene of differing agendas and tensions within the aspirational arena and the relationships between the main protagonists of government; business; society; and the individual. It also further 
illustrates, as previously discussed, the inherent difficulty in adequately and precisely defining the term "aspiration".

In summary, in the UK as a whole there is a strong assumption that raising aspiration levels in students will increase educational achievement, thereby aiding economic competitiveness and enhancing social equity (St Clair et al. 2013). In this context, aspiration can be seen as a key function of political policy making, and the framing of aspiration as a concept resides ultimately within the widest of macro-economic boundaries as governmental drives to promote and enable human capital, thereby fostering the knowledge economy (Rose \& Baird 2013).

FE is seen by government as a convenient agent in the skills change agenda. However, there appears to be a lack of clarity in fully understanding what aspiration means as well as a paucity of practical aspirational action to support this. Indeed, much of the research concerning aspiration and FE is critical of the sector describing it as "low-end institutions that advertise training for high end aspirations" (Zipin et al. 2015, 228). The overall tone in exploring aspiration within FE students can often reflect this bleakness. For example, Appadurai (2004) suggests that pragmatism must suffice against cruel optimism and stacked odds and Atkins $(2010,262)$ further reflects on an academic landscape of students that are opportunity-less, but exist in a vocational sector where illusory activities masquerade as learning in preparation for "low pay, low skill employment". MacLead (1995) concurs, suggesting aspirations have important roots in the "forbidding" class constraints on opportunity, highlighting one of the extrinsic variables at play here.

Reflecting this landscape, it appears that aspirational strategies within colleges are largely simplistic in design and posit holistic solutions such as trips and visits, guest speakers, the involvement of willing parents, and mentoring schemes and activities with an emphasis on extrinsically motivating students "to aspire", and are thus symptomatic of the primitive approach to a complex issue.

\section{Aspiration and Educational Policy - Gaps in Current Practice and Thinking}

The consistent line of governmental rhetoric in proposing an "aspiration nation" (DfE 2010) is underpinned by similar rhetoric that focuses on the specific claim that SES students can be supported to achieve and succeed within their educational journey through programmes of raising aspiration. This narrative remains largely undisputed, despite some aspects of educational enquiry suggesting that irrespective of background or class, young people in general terms harbour higher than expected aspirations (e.g., Archer et al. 2014). Appadurai $(2004,69)$ disagrees, suggesting that for WP and SES students in terms of navigational capacities, the least advantaged may have a reduced capacity to imagine a better future in a world where the most privileged groups dominate and where SES students have horizons of aspiration that are "brittle" (Appadurai 2004, 69). In a wider societal context, this is supported by Loveday (2015), who agrees that working-class under achievement is a cultural problem with an emphasis on individualism. This perspective suggests that it is the responsibility of the individual to aspire to succeed in life, while other constraints are minimised or ignored.

The aforementioned brittleness, however, is misleading and may only be an extrinsic limitation on a student's ability to achieve, not a measure of their capacity to aspire. Thornton et al. (2014) optimistically suggested that there is a move from recognising low aspirations in students and striving to raise them towards giving students the how to raise them. Whether the terminology regarding aspirations should be "influenced" rather than "raised" is an issue for further discussion, but research suggests that although the how is correctly emphasised, student aspirations are generally not low (Atkins 2009). If this is the case, then the logical response is to consider what is currently in place to enable students from all backgrounds to be equipped with the skills to attain their aspirations as well as a concurrent focus on what happens to student aspirations between the ages of 16 to 19 , the demographic intake age for FE colleges. The answer to the above question is very simple; in practical terms little is in place that resides under the banner of specific initiatives designed to raise aspiration. This is not to say that key stakeholders, such as colleges, management, teachers, parents and certainly government, are not focused on aspiration. Each in their own way have, or may have, a regard of differing emphasis for supporting student aspirations (Groot et al. 2017). Critically, however, what is currently absent but required is an integrated approach where these stakeholders work together in implementing practical strategies. The current reality suggests this is currently not the case. From a governmental agenda, FE colleges are measured in terms of student attainment and retention and achievement; likewise, teachers are measured on student attainment and engagement and motivation of students within the classroom (via observations and Ofsted criteria). These stakeholders therefore have aspirations for the students, but in doing so, in can be argued, work to their own agenda.

Managerialism within the sector has also positioned the student as consumer, with government and institutional targets underpinned by a funding and profit prerogative as well as a strategic need to simply "survive". Therefore, it is argued that the theme of aspiration is both peripheral and disingenuous in terms of any kind of practical strategy. Much like elite sport, where the focus is athlete-centred but coach-driven, in FE the student is akin to the athlete, but is at the whim of prevailing market forces. Further, Wallace $(2014,350)$ argues that the historic reputational status of FE colleges itself can help depress motivation in students, with origins for this at policy level and a market ideology that promotes a socially "ambivalent status to vocational education". In other 
words, students understand that they, and their learning and qualifications, are not valued in the same way as other post-16 qualifications such as A 'levels. This demotivating culture is amplified by issues of class and social status, given the high proportion of FE students with an SES background. It therefore comes as no surprise to learn that FE students are perceived to have lower aspiration levels than other post-16 equivalents (Baird et al. 2012). To acknowledge that this perception is potentially flawed, is also to acknowledge that FE colleges and successive governments have failed to collaboratively implement genuine and practical aspirational strategies. There is not just a gap in practice, therefore, but a gaping hole.

\section{Conclusion}

This paper argues for a more sophisticated debate around aspirations, with a need for practical outcomes that negate this prevailing and unquestioning impoverished deficit model currently surrounding FE in England and seeks to expose this predominant culture as inherently flawed (Campbell \& McKendrick 2017). Zipin et al. (2015, 228) suggest that simply raising aspirations as the panacea to overcoming life barriers and hurdles actually creates barriers by ignoring complexities and muting "the severities of historic conditions in which young people in underclass and working-middle-class positions struggle to imagine and pursue futures".

Currently, government advice for students to "raise their aspirations" is something of a catch-all approach intended to cover the maximum audience and persuade students to be optimistic, chase dreams and construct a compelling future. The reality is that an approach that attempts to target all can only ever reach a few, and thereby any practical aspirational strategy needs to acknowledge in its design an understanding of the target audience and build in measurable outcomes accordingly. Spohrer (2011) highlights how relevant literature and policy documents are usually based on large-scale quantitative studies, and reinforce the extrinsic influences of the family, including culture, environment and socialisation. Despite this understanding, most school-based aspirational initiatives target an individual's attitudes. Policy, therefore, may point to the importance of providing individually tailored guidance, and this may be an appropriate way forward in the search for how to "boost" aspiration. Indeed, if aspirations are indeed about imagined futures, then the individual student should be the key driver and influencer. Of course, a mix of political, economic, social, and personal factors (e.g., family, peers, education/school, class, and ethnicity) will inevitably act as structural influences on aspiration (Archer et al. 2010), but as Appadurai (2004, 69) states, "the capacity to aspire, like any complex cultural capacity, thrives and survives on practice, repetition, exploration, conjecture, and refutation." These facets are an example of how a collaborative relationship between student and college, underpinned by government financial and socio-economic strategy could be constructed, helping to promote and understand how to influence aspirations.

Moving forward, research in this area should consider how student perspectives of aspiration and life satisfaction can be better measured. There is also a need to enhance our understanding of the notion of aspirational deficit, including how aspirations can be brought to fruition over time. Similarly, a better understanding of influencing factors, such as socio economic drivers and policy, will help us to appreciate; (a) whether current practices are working, (b) whether students are equipped to maximise the initiatives in place, and (c) what we need to do to upskill students to strive and aspire. In essence, we need to be sure we are doing the right thing.

\section{References}

Anderson, R. (2017). Educating for our Economic Future, Education Policy Institute.

Appadurai, A. (2004). "The Capacity to Aspire: Culture and the Terms of Recognition". In Vijayendra, R. \& Walton, M. (eds.), Culture and Public Action. Stanford: Stanford University Press, 59-84.

Archer, L., Hollingworth, S. \& Mendick, H. (2010). Urban youth and schooling. Maidenhead: Open University Press.

Archer, L., Hollingworth, S. \& Halsall, A. (2007). 'University's not for me-I'm a Nike person': Urban, WorkingClass Young People's Negotiations of 'style', Identity and Educational Engagement. Sociology, 41(2), 219237.

Archer, L., DeWitt, J. \& Wong, B. (2014). "Spheres of Influence: What Shapes Young People's Aspirations at Age 12/13 and what are the Implications for Education Policy?", Journal of Education Policy, 29(1), 58-85.

Atkins, L. (2009). Invisible Students, Impossible Dreams: Experiencing Vocational Education 14-19. Stoke on Trent: Trentham Books.

Atkins, L. (2010). "Opportunity and Aspiration, or the Great Deception? The Case of 14-19 Vocational Education", Power and Education, 2(3), 253-265.

Baird, J., Rose, L. \& McWhirter, A. (2012). "So Tell Me What You Want: A Comparison of FE College and Other Post-16 Students' Aspirations." Research in Post-Compulsory Education, 17(3), 293-310.

Bourdieu, P. (1990a). The logic of practice. Stanford: Stanford University Press.

Cabinet Office (2009). New Opportunities: Fair Chances for the Future. Norwich: The Stationary Office.

Campbell, L, A. \& McKendrick, J. H. (2017). "Beyond Aspirations: Deploying the Capability Approach to Tackle 
the Under-Representation in Higher Education of Young People from Deprived Communities", Studies in Continuing Education, 39(2), 120-137.

Collins, D. (2015) Current Models of Collaboration - Post 14. London: Department for Business, Innovation and Skills.

Croll, P. (2008). "Occupational Choice, Socio-economic Status and Educational Attainment: A Study of the Occupational Choices and Destinations of Young People in the British Household Panel Survey", Research Papers in Education, 23, 243-268.

Croll, P. \& Attwood, G. (2013). "Participation in Higher Education: Aspirations, Attainment And Social Background", British Journal of Educational Studies, 61(2), 187-202.

Dennis, C.A. (2016). "Further Education Colleges and Leadership: Checking the Ethical Pulse", London Review of Education, 14(1), 116-130.

Department for Business, Innovation and Skills (2014). Further Education Workforce Strategy: The Government's Strategy to Support Workforce Excellence in Further Education. London: Department for Business, Innovation and Skills.

Department for Communities and Local Government., Cabinet Office. \& Department of Children, Schools and Families (2009). Inspiring Communities Grant Programme: Information Pack for Applicants, London: CLG.

DfE (2010). The Importance of Teaching - The Schools White Paper 2010. London: HMSO.

Eccles, J. (2009). "Who Am I and What Am I Going to do With My Life? Personal and Collective Identities as Motivators of Action", Educational Psychologist, 44, 78-90.

Elliot, A. \& Dweck, C. (2005). Handbook of Competence and Motivation. New York: Guildford Press.

Gale, T. \& Parker, S. (2015). "To Aspire: A Systematic Reflection on Understanding Aspirations in Higher Education", The Australian Educational Researcher, 42, 139-153.

Gorard, S., See, B. \& Davies, P. (2012). The Impact of Attitudes and Aspirations on Educational Attainment and Participation. York: Joseph Rowntree Foundation.

Grant, T. (2017). "The Complexity of Aspiration: The Role of Hope and Habitus in Shaping Working-Class Young People's Aspirations to Higher Education”, Children's Geographies, 15(3), 289-303.

Groot, B., Sanders, M., Rogers, T. \& Bloomenthal, E. (2017). I Get By with a Little Help from my Friends: Two Field Experiments on Social Support and Attendance in Further Education Colleges in the UK. Behavioural Insights Ltd.

HM Treasury \& DCSF (2007). Aiming High for Young People: A Ten-Year Strategy for Positive Activities. Norwich: Office of Public Sector Information.

Kaufman, S. (2014). From Evaluation to Inspiration. Scientific American. https://blogs.scientificamerican.com/beautiful-minds/from-evaluation-to-inspiration/

Keep, E. (2014). What Does Skills Policy Look Like Now The Money Has Run Out? London: Association of Colleges.

Kintrea, K., St Clair, R. \& Houston, M. (2015). "Shaped by Place? Young People's Aspirations in Disadvantaged Neighbourhoods", Journal of Youth Studies, 18(5), 666-684.

Kuczera, M., Field, S. \& Windisch, H. (2016). "Building Skills for All; A Review of England", OECD Skills Studies. OECD 2016.

Lea, J. Simmons, J. (2012). "Higher Education in Further Education: Capturing and Promoting HEness", Research in Post-Compulsory Education, 17(2), 179-193.

Loveday, V. (2015). "Working-Class Participation, Middle-Class Aspiration? Value, Upward Mobility and Symbolic Indebtedness in Higher Education”, The Sociological Review, 63(3), 570-588.

MacLeod, J. (1995) Ain't No Making It: Aspirations and Attainment in a Low Income Neighbourhood, $2^{\text {nd }}$ edition, Boulder: Westview Press.

Mather, K. \& Seifert, R. (2004) An Examination of Changes to the Labour Process of Further Education Lecturers. Wolverhampton: Management Research Centre, Wolverhampton University Business School.

May, T. (2018). PM: The Right Education for Everyone. https://www.gov.uk/government/speeches/pm-the-righteducation-for-everyone

Norris, E. \& Adam, R. (2017). All Change. London: Institute for Government.

Payne, J. (2003). Choice at the End of Compulsory Schooling: A Research Review. London: DfES Publications.

Quaglia, R. J. \& Cobb, C. D. (1996). "Toward a Theory of Student Aspirations", Journal of Research in Rural Education, 12(3), 127-132.

Randle, K. \& Brady, N. (1997). "Further Education and the New Managerialism", Journal of Further and Higher Education, 21(2), 229-239.

Richardson, W. (2007). "In Search of the Further Education of Young People in Post-War England", Journal of Vocational Education and Training, 59(3), 385-418.

Robinson, D. (2017). "Budget 2017: What it Could Mean for Higher (and Further) Education", https://www.timeshighereducation.com/blog/budget-2017-what-it-could-mean-higher-and-further-education 
Accessed 12 May 2018.

Rose, J. \& Baird, J. (2013). “Aspirations and an Austerity State: Young People's Hopes and Goals for the Future”, 11(2), 157-173.

Spohrer, K. (2011). “Deconstructing 'Aspiration': UK Policy Debates and European Policy Trends”, European Educational Research Journal, 10(1), 53-63.

Spohrer, K. (2016). "Negotiating and Contesting 'Success': Discourses of Aspiration in a UK Secondary School Discourse", Studies in the Cultural Politics of Education, 37(3), 411-425.

Stahl, G. (2012). "Aspiration and a Good Life Among White Working-Class Boys in London”, Journal of Ethnographic \& Qualitative Research, 7(1), 8-19.

St. Clair, R., Kintrea, K. \& Houston, M. (2013). "Silver Bullet or Red Herring? New Evidence on the Place of Aspirations in Education", Oxford Review of Education, 39(6), 719-738.

Strand, S. \& Winston, J. (2008). "Educational Aspirations in Inner City Schools", Educational Studies, 34(4), 249267.

Thornton, A., Pickering, E., Peters, M., Leathwood, C., Hollingworth, S. \& Mansaray, A. (2014). School and College-Level Strategies to Raise Aspirations of High-Achieving Disadvantaged Pupils to Pursue Higher Education Investigation. London: Department for Education.

UKCES (2016). Employer Skills Survey 2015: UK Results. London: UKCES.

Wallace, S. (2014). "When You're Smiling: Exploring How Teachers Motivate and Engage Learners in the Further Education Sector", Journal of Further and Higher Education, 38(3), 346-360.

Warner, D. \& Crosthwaite, E. (1995). Human Resource Management in Higher and Further Education. Milton Keynes: Open University Press.

Wilde, S. (2014). "Effects of parental involvement on academic achievement: a meta-synthesis", Educational Review, 66(3), 377-397.

Zipin, L., Sellar, S., Brennan, M. \& Gale, T. (2015). "Educating for Futures in Marginalized Regions: A sociological framework for rethinking and researching aspirations", Educational Philosophy and Theory, 47(3), 227-246. 